\title{
Universiteit
}

Leiden

The Netherlands

\section{From dormant to germinating spores of streptomyces coelicolor A3(2) new perspectives from the crp null mutant}

Piette, A.; Derouaux, A.; Gerkens, P.; Noens, E.E.E.; Mazzucchelli, G.; Vion, S.; ... ; Rigali, S.

\section{Citation}

Piette, A., Derouaux, A., Gerkens, P., Noens, E. E. E., Mazzucchelli, G., Vion, S., ... Rigali, S. (2005). From dormant to germinating spores of streptomyces coelicolor A3(2) new perspectives from the crp null mutant. Journal Of Proteome Research, 4(5), 1699-1708. doi:10.1021/pr050155b

Version: $\quad$ Publisher's Version

License: $\quad$ Licensed under Article 25fa Copyright Act/Law (Amendment Taverne)

Downloaded from: https://hdl.handle.net/1887/3239397

Note: To cite this publication please use the final published version (if applicable). 


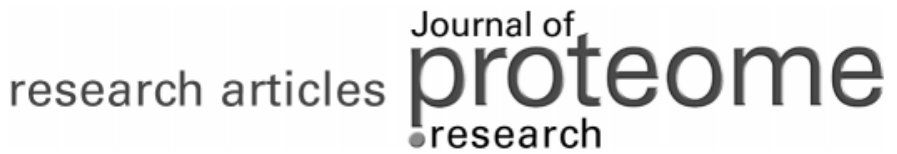

\section{From Dormant to Germinating Spores of Streptomyces coelicolor A3(2): New Perspectives from the crp Null Mutant}

\author{
André Piette, ${ }^{\dagger, \#}$ Adeline Derouaux, ${ }^{\dagger, \#}$ Pascal Gerkens, ${ }^{\ddagger}$ Elke E. E. Noens, ${ }^{\perp}$ Gabriel Mazzucchelli, ${ }^{\ddagger}$ \\ Sébastien Vion, ${ }^{\dagger}$ Henk K. Koerten, ${ }^{\perp}$ Fritz Titgemeyer, ${ }^{\circledR}$ Edwin De Pauw, ${ }^{\ddagger}$ Pierre Leprince,, \\ Gilles P. van Wezel, ${ }^{\perp}$ Moreno Galleni, ${ }^{*, \dagger}$ and Sébastien Rigali, ${ }^{*}+$
}

\begin{abstract}
Centre d'Ingénierie des Protéines, Université de Liège, Institut de Chimie B6a, Sart-Tilman, B-4000, Liège, Belgium, Mass Spectrometry Laboratory, Université de Liège, Allée de la Chimie 3, Sart-Tilman, B-4000 Liège, Belgium, Lehrstuhl für Mikrobiologie, Friedrich-Alexander-Universität Erlangen-Nürnberg, Staudtstrasse 5, 91058 Erlangen, Germany, Centre de Neurobiologie Cellulaire et Moléculaire, Université de Liège, Avenue de l'hôpital 1, Sart-Tilman, B-4000 Liège, Belgium, and Department of Biochemistry, Leiden Institute of Chemistry 2300RA Leiden, The Netherlands
\end{abstract}

Received May 27, 2005

\begin{abstract}
The complete understanding of the morphological differentiation of streptomycetes is an ambitious challenge as diverse sensors and pathways sensitive to various environmental stimuli control the process. Germination occupies a particular position in the life cycle as the good achievement of the process depends on events occurring both during the preceding sporulation and during germination per se. The cyclic AMP receptor protein (crp) null mutant of Streptomyces coelicolor, affected in both sporulation and germination, was therefore presented as a privileged candidate to highlight new proteins involved in the shift from dormant to germinating spores. Our multidisciplinary approach-combining in vivo data, the analysis of spores morphological properties, and a proteome study-has shown that $\mathrm{Crp}$ is a central regulatory protein of the life cycle in S. coelicolor; and has identified spores proteins with statistically significant increased or decreased expression that should be listed as priority targets for further investigations on proteins that trigger both ends of the life cycle.
\end{abstract}

Keywords: ADP-ribosylation • cAMP • Crp • germination • morphological differentiation • spore • streptomycetes

\section{Introduction}

Streptomycetes are Gram-positive soil bacteria with a complex life cycle that starts with the germination of a single spore, which grows out to form a branched mycelium of vegetative hyphae; morphological differentiation is initiated by wellcontrolled change from vegetative to aerial growth, and specialized sporogenic aerial hyphae then produce chains of hydrophobic spores. ${ }^{1}$ The spore or conidia is a practical means for dispersion and serves as a "safe house" for the genome in adverse environmental conditions. To restore vegetative growth, Streptomyces spores must be able to sense environmental changes that trigger the germination process. The molecular steps responsible for the emergence of germ tubes have not yet been identified, and in view of the bibliography dealing with this phenomenon, surprisingly little is known of this important period of the life cycle of organisms that serve as a model for

* To whom correspondence should be addressed. (S.R.) Tel: +324366 33 77. Fax: + 32436633 64. E-mail: srigali@ulg.ac.be. (M.G.) Tel: + 324 36635 49. Fax: + 32436633 64. E-mail: mgalleni@ulg.ac.be.

${ }^{\dagger}$ Centre d'Ingénierie des Protéines, Université de Liège.

‡ Mass Spectrometry Laboratory, Université de Liège.

${ }^{\S}$ Lehrstuhl für Mikrobiologie, Friedrich-Alexander-Universität ErlangenNürnberg.

"Centre de Neurobiologie Cellulaire et Moléculaire, Université de Liège.

${ }^{\perp}$ Department of Biochemistry, Leiden Institute of Chemistry.

\# These authors contributed equally to this work. bacterial development. One plausible explanation for this lack of data is that important difficulties are inherent to any conidial germination studies. In fact, diverse sensors and pathways, each one sensitive to a specific environmental stimulus, may control the process. In addition, it is difficult to differentiate between the true early signaling events and essential metabolic and housekeeping activities that occur at the very beginning of the process.

Since the early seventies and until recently, most approaches to examine the events associated with the germination triggering in streptomycetes were performed using metabolic inhibitors as no phase specific germination mutant was available. ${ }^{2}$ Generally, these results are difficult to interpret, as most inhibitors are not truly specific, but rather are influencing essential metabolic activities. Thus, it is not surprising that inhibition of protein synthesis (by chloramphenicol) or of respiration completely blocks spore germination in Streptomyces granaticolor and Streptomyces viridochromogenes, respectively. ${ }^{2,3}$ However, the use of metabolic inhibitors combined with a genomic approach has brought to light interesting data for the isolation of germination-specific components. Using the RNA polymerase inhibitor rifamycin, Mikulik and coworkers have demonstrated that dormant spores contain ribosomes and a pre-existing pool of mRNAs as template for protein synthesis in favorable conditions. ${ }^{2}$ About 15 proteins 
were synthesized from endogenous mRNA of the spores of $S$. granaticolor, and their identification could reveal which proteins are required at the very beginning of germination. As most bacterial signal transmitting proteins have kinase activities and receivers have phosphorylated or unphosphorylated states, attempts were made to detect whether these preexisting spores proteins exhibited such enzymatic activity. Cell-free extracts of dormant and germinating spores presented protein kinase activity, confirming that posttranslational modification of proteins by phosphorylation is involved in germination. ${ }^{2}$ Recently, Bobek and co-workers used a proteomic approach to monitor the activation and expression of proteins during germination of spores of $S$. granaticolor. ${ }^{4}$ Their work showed that major chaperones, such as DnaK, Trigger factor, and GroEL, were present in spores to assist the folding and presumably activate the aggregated spore proteins and participate in restoring ribosome functionality. They also present an overview of the metabolic activity of germinating spores by identifying the expression profile of glycolytic enzymes, enzymes of citric acid cycle, metabolism of amino acids and nucleic acids and components of the protein synthesis machinery.

Eventually, two germination-defective mutants (cya $a^{-}, \mathrm{BZ} 1$ strain and $\mathrm{crp}^{-}$, SAF1 strain) have been constructed in $S$. coelicolor ${ }^{5,6}$ The cya gene encodes the adenylate cyclase that synthesizes cAMP, and crp encodes a Crp/Fnr family transcription factor that interacts with cAMP. ${ }^{7}$ In the first part of the life cycle, both mutants present similar phenotypes, such as major loss of spore viability, resulting in important delays in germination and growth with more drastic effects in $\mathrm{crp}^{-}$than in $c y a^{-}$. However, in later steps of the morphological differentiation process cya and crp mutants behave in an opposite manner: on unbuffered media the cya mutant has a bald phenotype, referring to its inability to develop a fluffy aerial mycelium, while the crp mutant shows accelerated and enhanced sporulation. In conclusion, the analysis of the in vivo phenotypes of both germination-defective mutants indicated that cAMP is a key biomolecule responsible for correct spore germination in S. coelicolor. Hence, the crp mutant can be considered as a privileged strain to study and identify the functional elements responsible for triggering germination. However, as sporulation seems to be also affected in the crp mutant, it remains to be seen whether the observed problem during germination has its origin in events occurring during the germination process per se or already from altered sporulation leading to abnormal spores unable to germinate.

In the first part of the present work, we provide new evidence showing that the Cya/cAMP/Crp system is not limited to germination control as it centrally affects the different steps of the developmental process. Then, we used two-dimensional (2D) gel electrophoresis to compare the protein expression pattern during the early moments preceding the germ tube emergence in the dormant spore of S. coelicolor A3(2) M145 and the $\operatorname{crp}$ mutant. The identification of proteins with modified expressions in concert with in vivo studies and the analysis of the morphological properties of the crp mutant spores have highlighted targets for further investigations on genes involved in the shift from the dormant to the germinating spore.

\section{Experimental Section}

Growth Conditions. Streptomyces coelicolor A3(2) M145 (SCP1 $^{-} \mathrm{SCP}^{-}$prototroph) was grown on R2YE plates with cellophan disks ${ }^{8}$ in order to collect mycelium and prepare crude protein extracts for Western blotting, or on SFM agar plates for microscopic observations. For proteomic studies, Streptomyces coelicolor A3(2) M145 and SAF1 (crp mutant) spores (100 mg wet weight) were cultured at $28^{\circ} \mathrm{C}$ in $20 \mathrm{~mL} 2 \times$ YT medium in a shaken $250 \mathrm{~mL}$ flask $(300 \mathrm{rpm}){ }^{8}$ Germinated spores were then collected by centrifugation $(1000 \times g)$, frozen in an ethanol/dry ice bath and stored at $-70{ }^{\circ} \mathrm{C}$ before subsequent processing.

Preparation of Crude Proteins Extracts and Western Blot Analysis. Harvested mycelium was resuspended in water and disrupted by sonication in a Branson ultrasonic disintegrator at a $12 \mu \mathrm{m}$ amplitude for three $30 \mathrm{~s}$ bursts. The soluble fraction was obtained by centrifugation $(16000 \times g$, $30 \mathrm{~min})$ of the lysate. Determination of protein concentrations was performed using the 2-bicinchoninic acid assay (BCA protein assay; Pierce). The Western blot analysis was performed as described previously. $^{7}$

Preparation of Protein Extracts from Spores. Spores were washed twice in $20 \mathrm{~mL}$ of a buffer containing $10 \mathrm{mM}$ Tris- $\mathrm{HCl}$ (pH 8) and $5 \mathrm{mM}$ magnesium acetate. They were then disrupted by sonication $(10 \times 30 \mathrm{~s}$ pulses at $7.5 \mu \mathrm{m})$ in $500 \mu \mathrm{L} 0.1 \mathrm{M}$ Tris$\mathrm{HCl}$ (pH 7.6), $10 \mathrm{mM} \mathrm{MgCl}_{2}, 6 \mathrm{mM}$ DTT, $1 \mathrm{mM}$ PMSF in the presence of $300 \mu \mathrm{g}$ of glass beads $\left(0.1-0.2 \mathrm{~mm}\right.$ diameter). ${ }^{8}$ Protein extracts were clarified by centrifugation $(30000 \times g$, $30 \mathrm{~min}$ at $4{ }^{\circ} \mathrm{C}$ ) and the proteins were precipitated in $10 \%$ trichloroacetic acid and $0.02 \%$ sodium deoxycholate (final concentrations). The protein pellets were washed twice with $500 \mu \mathrm{L}$ ice cold acetone and dried in a vacuum centrifuge.

Construction of a Crp Overproducing Strain (SAF2). For overproduction of Crp in S. coelicolor, the cloning was achieved by PCR with oligonucleotides 5'-CCAGATCTGTGGACGACGTTCTGCGGCGC-3' (BglII site italicized) and 5'-CTGCAGTCAGCGGGAGCGCTTGGCCAGTCG-3' (PstI site italicized). The $687 \mathrm{bp}$ PCR product was first cloned in pGEM-T Easy for DNA sequencing and then digested with BglII and PstI and subcloned into the high-copy shuttle-vector Vpro p145.10. ${ }^{9}$ The resulting crp constitutive expression plasmid was designated pCIP267. pCIP267 was transferred into S. coelicolor wild-type M145 by protoplast transformation ${ }^{8}$ resulting in the SAF2 strain (or $\mathrm{crp}^{+++}$).

Production and Purification of Crp. The production and purification of his-tagged Crp in Escherichia coli was performed as described previously. ${ }^{7}$

Two-Dimensional Differential In-Gel Electrophoresis (2DDIGE). Precipitated proteins were solubilized in $100 \mu \mathrm{L}$ of 30 $\mathrm{mM}$ Tris (pH 9), $7 \mathrm{M}$ urea, $2 \mathrm{M}$ thiourea, $2 \%$ amidosulfobetaine14 (ASB-14). The pooling of equal amounts of every sample of the experiment constituted the internal standard. $50 \mu \mathrm{g}$ of each sample were labeled with $400 \mathrm{pmol}$ of Cy2 CyDye (internal standard), Cy3 CyDye (SAF1 mutant) or Cy5 CyDye (wild-type M145), according to the manufacturer's instructions (Amersham Biosciences). Combination of two labeled replicates and the internal standard were then made and diluted twice with $7 \mathrm{M}$ urea, $2 \mathrm{M}$ thiourea, 2\% ASB-14, 2\% dithiothreitol, 2\% IPG buffer $\mathrm{pH} 4-7$ and loaded by $12 \mathrm{~h}$ passive rehydration in 24 cm-long IPG drystrip pH 4-7 isoelectrofocusing gels (Amersham Biosciences). Proteins were focused using an IPG Phor apparatus (Amersham Biosciences) with a 3-step program (final step at $8000 \mathrm{~V}, 68000 \mathrm{Vh}$ total). Second dimension separation on the basis of mass was performed on denaturing $12.5 \%$ SDSPAGE gels in an Ettan DALT six electrophoresis unit (Amersham Biosciences). Gels were imaged in three colors with a Molecular Dynamics Typhoon 9400 laser scanner. 
Gel Analysis. Gels were analyzed with DeCyder software (Amersham Biosciences). Intensity of each spot was expressed as a function of that of the corresponding codetected internal standard spot. After spot matching between all the gels of the experiment, significant differences between each spot in each sample were determined using a one-way analysis of variance test (ANOVA) with a $p$-value equal to 0.05 .

Tryptic In-Gel Digestion. Gels were stained with ruthenium(II) tris-bathophenantroline disulfonate $\mathrm{e}^{10,11}$ and spots were excised on a UV table. Gel pieces were washed with $100 \mu \mathrm{L}$ of $25 \mathrm{mM} \mathrm{NH}_{4} \mathrm{HCO}_{3}$ and dehydrated in $100 \mu \mathrm{L}$ acetonitrile, three times alternatively, before being dried in a vacuum centrifuge. Gel pieces were incubated in $30 \mu \mathrm{L}$ of $10 \mathrm{mM}$ dithiothreitol (DTT) in $25 \mathrm{mM} \mathrm{NH}_{4} \mathrm{HCO}_{3}$ at $56{ }^{\circ} \mathrm{C}$ for $45 \mathrm{~min}$, and then in 30 $\mu \mathrm{L}$ of $55 \mathrm{mM}$ iodoacetamide in $25 \mathrm{mM} \mathrm{NH}_{4} \mathrm{HCO}_{3}$ for $45 \mathrm{~min}$ at room temperature. Subsequently, proteins were in-gel digested with $12.5 \mathrm{ng} / \mu \mathrm{L}$ trypsin (Promega) in $\mathrm{NH}_{4} \mathrm{HCO}_{3}(\mathrm{pH}$ 8.2) at 30 ${ }^{\circ} \mathrm{C}$ for $16 \mathrm{~h}$. Supernatants were collected, $20 \mu \mathrm{L}$ of a mixture of $5 \%$ formic acid, $50 \%$ acetonitrile and $45 \%$ water was added to the gel pieces and remaining peptides were extracted by sonicating the gel pieces for $10 \mathrm{~min}$ in a sonication bath. This extraction step was repeated twice, the supernatants were pooled and subsequently dried in a vacuum centrifuge.

Mass Spectrometry Analysis. Peptides separation by reversedphase liquid chromatography was performed on an Ultimate LC system (LC Packings) complete with Famos autosampler and Switchos II microcolumn switching device for sample cleanup and preconcentration. Sample ( $30 \mu \mathrm{L})$ was loaded at a flow rate of $200 \mathrm{~nL} / \mathrm{min}$ on a micro-precolumn cartridge (300 $\mu \mathrm{m}$ i.d. $\times 5 \mathrm{~mm}$, packed with $5 \mu \mathrm{m} \mathrm{C18} 100 \AA$ PepMap). After $5 \mathrm{~min}$, the precolumn was connected with the analytical nanocolumn $(75 \mu \mathrm{m}$ i.d. $\times 15 \mathrm{~cm}$, packed with C18 PepMap100, 3 $\mu \mathrm{m}, 100 \AA$ ) and the gradient started. Elution gradient varied from 0 to $30 \%$ buffer B over $30 \mathrm{~min}$, buffer A is $0.1 \%$ formic acid in acetonitrile/water 2:98 ( $\mathrm{vol} / \mathrm{vol}$ ) and buffer B is $0.1 \%$ formic acid in acetonitrile/water 20:80 ( $\mathrm{vol} / \mathrm{vol})$. The outlet of the LC system was directly connected to the nano electrospay source of an Esquire HCT ion trap mass spectrometer (Bruker Daltonics, Germany). Mass data acquisition was performed in the mass range of 50 to $1700 \mathrm{~m} / \mathrm{z}$ using the Standard-Enhanced mode $(8100 \mathrm{~m} / \mathrm{z}$ per sec). For each mass scan, a datadependent scheme picked the four most intense doubly or triply charged ions to be selectively isolated and fragmented in the trap and the resulting fragments were mass analyzed using the Ultra Scan mode $(50-3000 \mathrm{~m} / \mathrm{z}$ at $26000 \mathrm{~m} / \mathrm{z}$ per sec).

Raw data were analyzed and formatted (Data Analysis software, Bruker) for subsequent protein identification against the translated $S$. coelicolor genome database through MS/MS ions search algorithm on the Mascot search engine (www.matrixscience.com). The mass tolerance of precursor and sequence ions was set at 0.5 and $0.3 \mathrm{Da}$, respectively, and carbamidomethylation of cysteines and methionine oxidation were set as fixed and variable modifications, respectively. The identification of a protein was considered significant when ions with scores higher than 23 were detected in the mass spectrum $(p<0.05)$. Further details are provided in the table joined as Supporting Information.

Electron Microscopy. Morphological studies of surfacegrown aerial hyphae and spores of S. coelicolor M145 and mutant derivatives by cryo-scanning electron microscopy (cryoSEM) was performed as described previously, using a JEOL JSM6700F scanning electron microscope. ${ }^{12}$ Transmission elec-

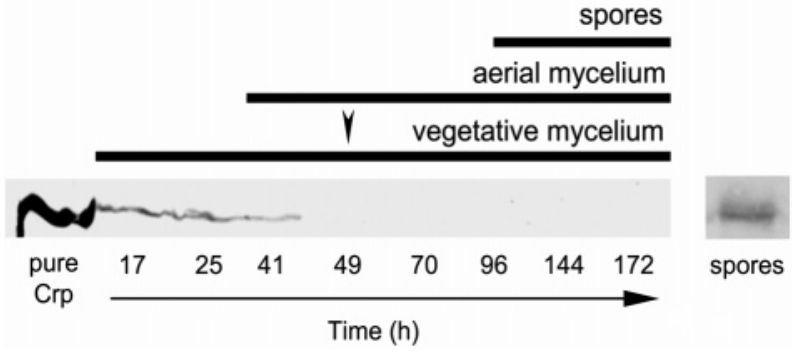

Figure 1. Life cycle dependent expression of Crp in S. coelicolor. Western blot analysis with anti-Crp antibodies on the soluble fractions from cells collected at different time points. Horizontal lines represent the approximate time points when vegetative mycelium, aerial mycelium or spores are present. The arrow indicates the beginning of $\gamma$-actinorhodin production.

tron microscopy (TEM) for the analysis of cross-sections of hyphae and spores was performed with a Philips EM410 transmission electron microscope as described previously. ${ }^{13}$

\section{Results and Discussion}

Crp is Involved in All Steps of Morphological Development. The consequences of the crp gene disruption on morphological development of $S$. coelicolor (impaired in germination and hypersporulation) prompted the monitoring of the expression of Crp throughout the life cycle (Figure 1). R2YE plates were inoculated with $50 \mu \mathrm{L}$ of spore suspension (around $6 \times 10^{7}$ spores) and incubated at $28{ }^{\circ} \mathrm{C}$. Mycelia grown on cellophane disks were collected at different developmental stages; vegetative mycelium (17 h), the onset of aerial growth (41 h), onset of actinorhodin production (49 h), sporulation (96 h), and full sporulation (7 days). Western blot analyses on these total protein extracts showed that Crp is only present in the first part of the life cycle, until the time that aerial hyphae emerged (Figure 1). At the moment that the blue-pigmented actinorhodin became visible, Crp was no longer detectable. Using cellophane disks, all types of cells (vegetative mycelia, aerial hyphae, and spores) were collected, but protein extracts of the vegetative fraction represents a large majority in our samples. When proteins were extracted from only spore samples without mycelia contamination, we detected the Crp protein, suggesting a later synthesis once the sporulation process has been triggered (Figure 1). In YEME liquid media, where no morphological differentiation is observed, Crp is present throughout the culture (data not shown). Hence, Crp presents a life-cycledependent expression profile that is in agreement with its expected necessary role at both start and end of the life cycle.

To provide additional evidences for a role of Crp in morphological differentiation, we subcloned the coding sequence of crp on a high-copy-number plasmid and introduced it (pCIP267) into the parental strain M145 giving strain SAF2 $\left(c r p^{+++}\right.$strain). We observed previously that introduction of the same vector without the insert did not provoke any phenotypical change in S. coelicolor. Clones resulting from pCIP267 protoplasts transformation were cultivated for 2 days in YEME and overexpression of Crp was confirmed by Western blot analysis (Figure 2B). The phenotype of SAF2 was further investigated on R2YE plates. The vegetative growth was not affected in SAF2 compared to the wild type M145. Production of blue actinorhodin was precociously visible in SAF2 strain (Figures 2C) that further presented a "bald" phenotype (no sporulation and no aerial hyphae, Figure 2A). This result 


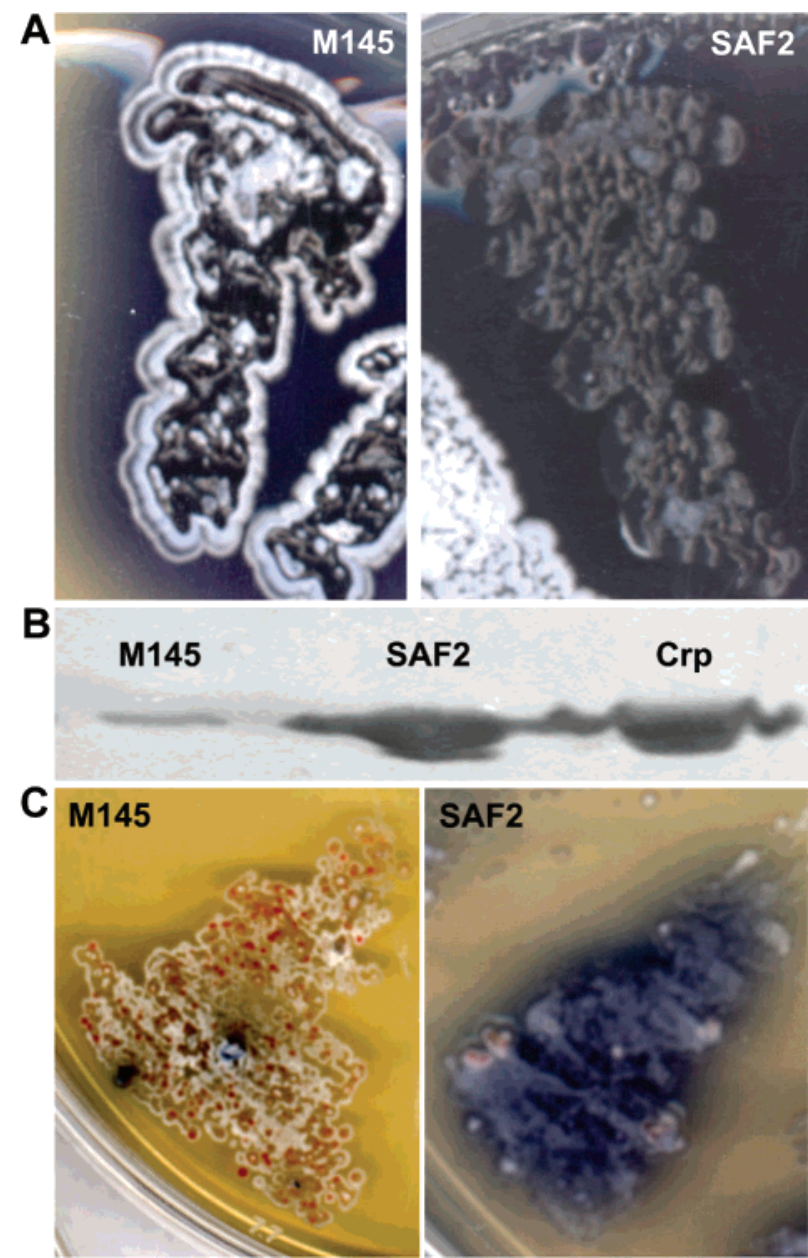

Figure 2. Phenotype of the Crp overproducing strain (SAF2). (A) Bald phenotype of the SAF2 strain compared to the wild type $S$. coelicolor A3(2) M145 incubated 6 days at $28^{\circ} \mathrm{C}$ on R2YE plates. (B) Western blot analysis with anti-Crp antibodies on the soluble fractions collected from the wild type (M145), the Crp overproducing strain (SAF2), and on purified His-tagged Crp (Crp). (C) Precocious $\gamma$-actinorhodin production in mutant SAF2 compared to M145 incubated 2 days at $28^{\circ} \mathrm{C}$ on R2YE plates.

together with the hypersporulation phenotype of the $\mathrm{crp}^{-}$strain (SAF1), ${ }^{6}$ suggests that the presence of Crp somehow prevents morphological differentiation and therefore blocks the life cycle at the vegetative mycelia step. In addition, comparing the $c r p^{+++}$and the $c r p^{-}$strains, we also observed opposite phenotypes regarding the production of actinorhodin (reduced and delayed for $\mathrm{crp}^{-}$, and early and activated for $\mathrm{crp}^{+++}$).

Morphology of the $\operatorname{crp}$ Mutant Spores. We just showed that Crp is involved in the different steps of the life cycle. As both beginning (germination) and end (sporulation) of development are affected in the crp null mutant it was of interest to resolve whether the observed delay in growth relates to events altering sporulation leading to abnormal spores unable to germinate. We therefore analyzed the morphologies of crp mutant spores in more detail. Spores from fully developed colonies (grown for 7 days on SFM agar plates) were therefore subjected to scanning and transmission electron microscopy. Expectedly, the crp mutant produced visible amounts of vegetative mycelium approximately $24-30 \mathrm{~h}$ later than the parental strain M145 (35-42 h vs $12-14 \mathrm{~h}$, respectively). Scanning Electron microscopy (SEM) confirmed earlier observations that mutation of crp does interfere with sporulation per se, as spores were more abundant and generally larger (turgescent aspect) to those of the parent M145 (Figure 3A). All spores were coated with a rodlet layer. Interestingly, high-resolution analysis of thin sections of the crp mutant by transmission electron microscopy (TEM) revealed several striking differences with the parental strain (Figure 3B). The most obvious differences were that all spores of the crp mutant had a very thick and 'light' (more electron lucent) spore wall, and condensed chromosomes could not be visualized in the crp mutant, while nucleoids (marked as $\mathrm{N}$ in Figure 3B) were readily visible in M145. Furthermore, the spore shapes were much more heteromorphous than those of M145, and almost all spores were coated with a ring of dark material of unknown composition (indicated by small arrows in Figure 3B). To further substantiate the enhanced thickness of the spore walls, the walls were measured. The wild-type strain had a spore wall that took up between 4 and $6 \%$ of the spore width, with an average width of $37 \mathrm{~nm}$ (38 spores measured). For the $c r p$ mutant, the width of the spore walls was between 8 and $15 \%$ of the width of the spore, with an average width of $80 \mathrm{~nm}$ (54 spores measured). Hence, the crp mutant produced spores with a spore wall approximately doubled thickness compared to the parental strain. Considering that the first step in the germination process is autolysis of the spore wall peptidoglycan, the very thick spore wall explains at least in part why crp mutants germinate so occasionally.

The Proteomic Approach. To provide maximal information on proteins associated with the early steps preceding germ tube emergence, we undertook a comparative proteome analysis. We decided to apply the proteomic approach to dormant spores as the starting point in order to ensure the analysis of cells at identical moment of their life cycle and therefore to render a comparative study possible between the wild type and the mutant. We first tested the proteome analysis with samples collected at 0,1 , and $2 \mathrm{~h}$ after spores activation, but changes in expression profiles within strains were insignificant (data not shown). The changes in spot intensity were then evaluated between dormant spores and 3 and $5 \mathrm{~h}$ activated spores. The comparison of the profiles between dormant spores of the wild type and the $\operatorname{crp}$ mutant will establish the initial situation, telling us whether spores start the germination process in similar condition or whether, as suggested from the analysis of spore sections, drastic changes in spore-protein composition contribute to the impaired germination of the crp mutant. The comparison of the profiles between the two strains after 3 and $5 \mathrm{~h}$ would principally indicate whether proteins translating the awakening of central metabolic pathways are correctly reactivated in the crp mutant. A typical multiplexing distribution of protein spots in dormant spores of the wild type and the crp mutant is presented in Figure 4.

We focused our analysis on protein spots that showed more than a 2-fold variation of expression within a strain and/or between strains, in at least one of the three time points. This threshold was selected to be certain that the induction is significant. According to this criterion, 144 spots were selected of which 92 presented sufficient material for analysis. A total of 72 spots contained only one protein, which correspond to a total of 45 different proteins. In fact, several proteins were found in different spots as a probable result of post-translational modifications. The identified proteins are listed in Table 1 according to their functional groups. In the wild-type strain, 19 proteins showed an increased expression profile (two- to nine-fold) after restoration of favorable conditions (at 3 and 5 

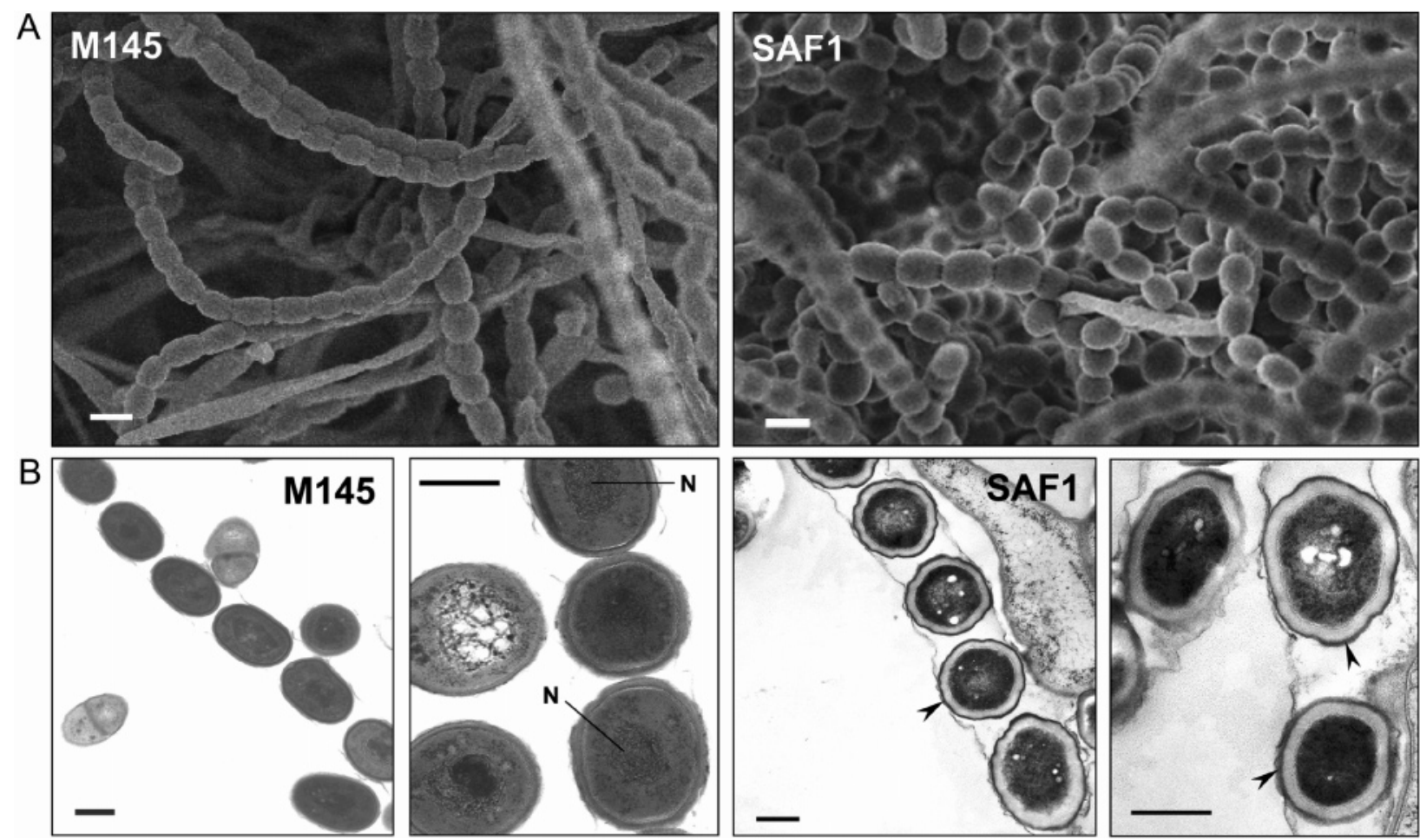

Figure 3. Analysis of the spore morphology of the crp mutant (SAF1). (A) Scanning electron microscopy of the wild-type M145 (left) and the SAF1 mutant (right) spores. Scales bars represent $1 \mu \mathrm{m}$. (B) Transmission electron microscopy of spores thin sections of the wild-type M145 (left) and the SAF1 mutant (right). Nucleoids are marked as N and small arrows indicate the ring of electron dense material of unknown composition. Scales bars represent $500 \mathrm{~nm}$.

h time points), while the amount of 10 proteins was significantly reduced (from two- to nineteen-fold). In the $\mathrm{crp}$ mutant only eight proteins showed a weak increased profile (from twoto four-fold) and 12 proteins presented a decrease (from twoto ten-fold).

Low Reactivation of Essential Metabolic Activities in the crp Mutant. The identification of proteins involved in essential metabolism pathways (protein synthesis, transcription machinery, and the respiratory chain) translates a general lower response to spore activation in mutant SAF1. We first focused our analysis on the activation of the translational system as in the first steps of germination, ribosomal proteins in spores are necessary to translate the pre-existing pool of mRNA. ${ }^{2}$ Some of the proteins encoded by this pre-existing pool are supposed to be essential for the initiation of the early steps of germination. Our proteomic analysis revealed that three ribosomal proteins, namely RspD (30S ribosomal protein S4, SCO1505, spot 1301), a ribosomal L25p family protein (SCO3124, spot 1312), and RplL (50S ribosomal protein L7/L12, SCO4653, spot 1655) were present in relatively high amounts in SAF1 and their quantity remained approximately constant over time. In the parental strain, their amount is low compared to SAF1 and two of them strongly increased after activation of spores. The presence of soluble ribosomal proteins in the mutant suggests that the translation of a presumed pre-existing pool of mRNA is not the limiting step and might not explain the impaired germination in the crp mutant. However, the expression of other elements for correct protein synthesis were found to be affected in mutant crp. Protein chaperones GroEL1 (SCO4762, spots 342, 346, and 351) and GroEL2 (SCO4296, spots 348, 358, and 359) and DnaK (SCO3671, spots 233, 234, and 245) all showed induced expression profiles in S. coelicolor wild type.
Similar data were already observed for GroEL, DnaK, and Trigger factor in S. granaticolor ${ }^{4}$ and their phosphorylation and dephosphorylation have been suggested as critical steps for the solubilization of aggregates of misfolded spores proteins. The same group proposed that they are essential for the reactivation of ribosomal proteins and the folding of proteins synthesized de novo. ${ }^{4}$ In the $\operatorname{crp}$ mutant, we observed a decrease of these chaperones, suggesting negative effects on correct protein folding. In addition, the elongation factors EF-Ts (SCO5625, spot 931) and EF-P (SCO1491, spot 1287) are also significantly under-represented in mutant SAF1.

In S. granaticolor, transcription also occurs in the first minutes of activation of spores and the RNA polymerase inhibitor rifamycin blocks the germination process. ${ }^{2}$ We found that the DNA-directed RNA polymerase alpha chain (SCO4729, spot 728) showed a constant increase in the wild type M145. In mutant SAF1, the amount is relatively similar at time zero but it decreases significantly after the reactivation of spores. Therefore, like the translational system, the transcriptional machinery seems also to be altered in the crp mutant.

Previous experiments using inhibitors of the respiratory chain showed that active ATP synthesis and energy were required for the triggering of the germination process in $S$. viridochromogenes. ${ }^{3}$ In addition, cAMP that is produced from ATP by the action of the adenylate cyclase is known to be a key biomolecule for the germination in S. coelicolor. ${ }^{5,6}$ In the wild-type M145, we observed that three spots (367, 372, and 377) corresponding to the alpha subunit of the ATP synthase (SCO5371) showed an increasing profile while the spots in SAF1 showed a decreasing one. The low amount of ATP synthase in the mutant should provoke a double penalizing effect on spores 


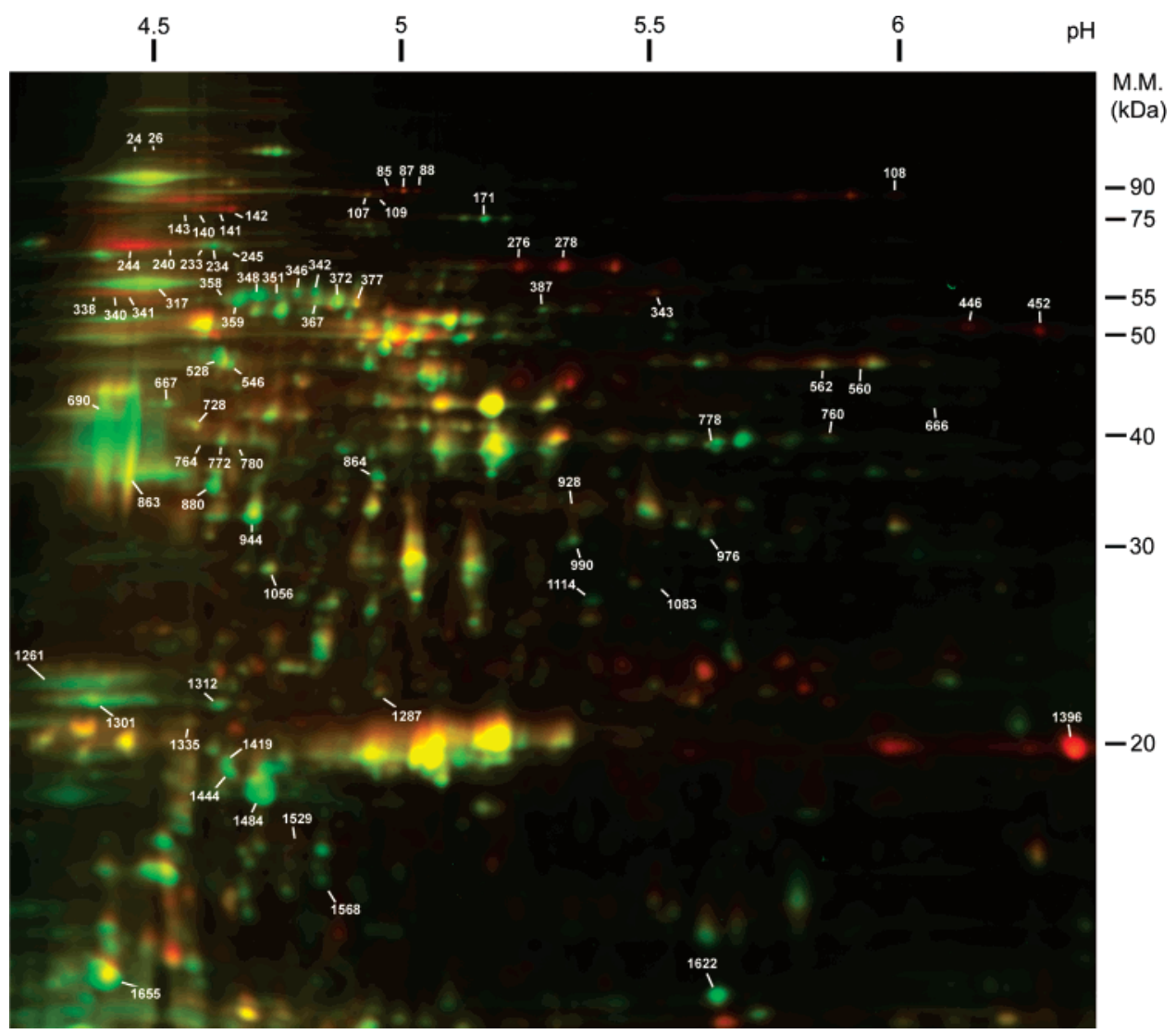

Figure 4. Multichannel picture of a representative 2D-DIGE gel. Dormant spores soluble extracts in pH range 4-7. Wild-type in red (Су5), and crp mutant in green (Су3).

germination: low energy source for the reactivation of central metabolic pathways and a low pool of substrate for cAMP synthesis.

Proteomic Data and Phenotypes of the crp Mutant. Our mutant based approach is diametrically opposite to previous germination studies based on the use of metabolic inhibitors. This allow us point out putative germination or sporulation specific proteins as interesting tracks to explain some of the known phenotypes of the crp mutant.

We notably reported that mutant SAF1 shows an early and activated morphological differentiation. In S. coelicolor, the nucleotide ppGpp plays an important role in the induction of morphological differentiation under conditions of nitrogen limitation. ${ }^{14}$ The deletion of relA, coding for the ppGpp synthetase, gives rise to a strain that shows a marked delay in the onset and extent of morphological differentiation. However, in our case, the presumed limitation of ppGpp does not provoke the expected delay, as the phenotype of SAF1 rather tends to show a precocious morphological differentiation. A decrease of GTP has been proposed as a critical parameter to initiate morphological differentiation in several Streptomyces spp. ${ }^{15}$ The fact that the amount of inosine $5^{\prime}$ monophosphate (IMP) dehydrogenase-directly involved in the synthesis of GTP-is particularly low could explain in part the SAF1 phenotype.

Another part of the answer for the accelerated differentiation could arise from the identification of PstS (SCO4142, spots 863, 880, and 944) in the soluble fraction of the crp mutant. PstS is involved in phosphate transport and consists of the ligandbinding element of ATP-binding cassette (ABC) transporters. This type of protein should not have been detected through our method of protein preparation, as it possesses a membrane lipid-anchoring region in its N-terminal part. The intracellular localization of PstS should prevent its function in phosphate transport. Interestingly, the inactivation of pstS in S. coelicolor impaired phosphate transport and leading to accelerated differentiation and sporulation, a phenotype very similar to the one of the crp mutant. ${ }^{16}$

In addition, our proteomic analysis identified in spot 1396 a protein (SCO5466) that may be involved in cell wall autolysis and therefor explain why the crp mutant has a cell wall approximately twice the width of the spores produced by the parental strain (Figure 3B). In fact, SCO5466 is homologous to many bacterial cell wall hydrolases. The search for conserved motifs revealed a two-domain organization: (i) the N-terminal part belongs to the glycosyl hydrolases family 25 and (ii) the C-terminal part contains a peptidoglycan-binding domain. Members of the family 25 of glycosyl hydrolases are exclusively lysozyme precursors (1,4-beta- $N$-acetylmuramidase M1) with sequence $D$-[LIVM]-x(3)-[NQ]-[PGE]-x(9,15)-[GR]-x(4)-[LIVMFY](2)-K-x-[ST]-E-[GS]-x(2)-[FYL]-x-[DN] ( $D$ and $E$ are active site residues) as the consensus pattern. The amount of this protein is very high within dormant spores of the wild type strain, and then it decreases drastically after reactivation of spores. In contrast, the protein was almost absent in spores of the crp mutant and the level remained very low at the other time points of our analysis. Because of the lysozyme-like function of SCO5466 and its high abundance in M145 spores, it is a privileged candidate to explain the observed thick cell wall of spores of the crp null mutant that would lead to the important delay of germ tube emergence. Interestingly, a transcriptome analysis also revealed that orf SCO5466 was expressed in a sporulation-dependent manner, suggesting that indeed it may 
Table 1. Identified Proteins Expressed in Dormant and Germinating Spores of Both S. coelicolor M145 Type and SAF1 Strains ${ }^{a}$

\begin{tabular}{l}
\hline Identified protein \\
(gene number) \\
\hline Protein translation \\
Elongation factor P, EFP \\
(SCO1491) \\
30s ribosomal protein s4 \\
(SCO1505) \\
Ribosomal L25p family protein \\
(SCO3124) \\
50s ribosomal protein L7/L12 \\
(SCO4653) \\
Elongation factor Ts, EF-Ts \\
(SCO5625) \\
Heat shock proteins, chaperones \\
Heat shock protein 70, DnaK \\
(SCO3671) \\
Chaperonin 2, GroEL2 \\
(SCO4296) \\
Chaperonin cpn60, GroEL1 \\
(SCO4762) \\
Peptidyl-prolyl cis-trans isomerase \\
(SCO7510) \\
Carbohydrate metabolism \\
Probable L-alanine dehydrogenase \\
(SCO1773) \\
Probable transketolase A1 \\
(SCO1935) \\
Probable dehydrolipoamide dehydrogenase \\
(SCO2180) \\
Putative secreted hydrolase, agarase \\
(SCO3487) \\
Phosphoglyceromutase \\
(SCO4209) \\
Succinyl-CoA synthetase beta chain \\
(SCO4808) \\
Succinyl-CoA synthetase alpha chain \\
(SCO4809) \\
Transketolase A2 \\
Neotide metabolism \\
(S)
\end{tabular}

Putative xanthine oxidoreductase, large subunit (SCO0691)

Inosine 5' monophosphate dehydrogenase (SCO4770)

Putative inosine 5 ' monophosphate dehydrogenase (SCO4771)

Bifunctional purine biosynthesis protein (SCO4814)

Guanosine pentaphosphate synthetase (SCO5737)

Transport of small molecules

Sugar-binding lipoprotein (SCO2978)

Phosphate-binding lipoprotein, PstS (SCO4142)

Oligopeptide-binding lipoprotein (SCO5477)

\section{Proteases}

20s proteasome alpha subunit (SCO1643)

Putative serine protease (SCO2637)

Probable M18-family amino-peptidase 2 (SCO3801)

ClpC2 proteinase ATP binding chain (SCO6408)
Evolution of quantity in M145

SAF1

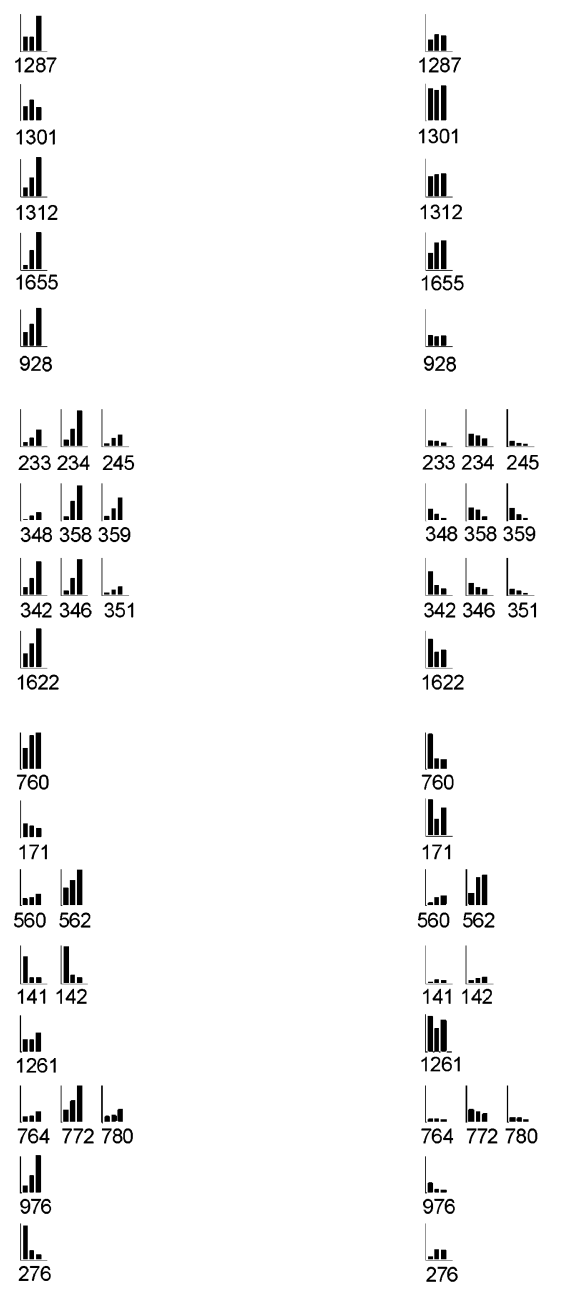

$\left.\underset{108}{140} \ln _{140}\right|_{14}$

|ll| |||

446452

${ }_{778}^{\text {III }}$

$\underset{387}{|| l \mid}$

|ll| $\mid$ |l,

$\left.\frac{L}{108}\right|_{140} \mid .$.

$L 446452$

|l|

778

|lI

107109

$\underset{690}{\ln }$

$\frac{\prod_{863}|\ldots| .1}{880} \frac{111}{944}$

$\|_{690}$

$\frac{\prod_{27}}{278}$

||l| |l| $\frac{|| \mid}{863}$

III

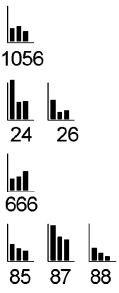

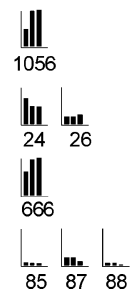


Table 1. (Continued)

\begin{tabular}{|c|c|c|}
\hline $\begin{array}{l}\text { Identified protein } \\
\text { (gene number) }\end{array}$ & $\begin{array}{l}\text { Evolution of quantity in } \\
\text { M145 }\end{array}$ & SAF1 \\
\hline \multicolumn{3}{|l|}{ Unclassified } \\
\hline $\begin{array}{l}\text { Hypothetical protein } \\
\text { (SCO0919) }\end{array}$ & $\mid \frac{11}{528} \underset{546}{\mid .11}$ & \begin{tabular}{l|l} 
l. \\
528 \\
546
\end{tabular} \\
\hline $\begin{array}{l}\text { Putative alkaline stress-like protein } \\
\text { (SCO1836) }\end{array}$ & $\frac{\mid \|}{1529}$ & $\frac{11}{1529}$ \\
\hline $\begin{array}{l}\text { Dephospho-CoA kinase } \\
\text { (SCO1996) }\end{array}$ & $\operatorname{lll}_{1335}$ & $\underset{1335}{111}$ \\
\hline $\begin{array}{l}\text { Probable secreted alkaline phosphatase } \\
\text { (SCO2068) }\end{array}$ & 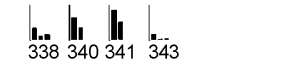 & 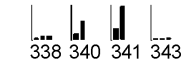 \\
\hline $\begin{array}{l}\text { Probable bacterioferritin } \\
\text { (SCO2113) }\end{array}$ & $\frac{1 . . .}{1444} 1484$ & $\underset{1444}{\ln } \|_{1484}$ \\
\hline $\begin{array}{l}\text { Probable inorganic pyrophosphatase } \\
\text { (SCO3409) }\end{array}$ & $\operatorname{lil}_{1419}$ & $\|_{1419}^{\|}$ \\
\hline $\begin{array}{l}\text { Putative integrated membrane regulator } \\
\text { (SCO3583) }\end{array}$ & $\frac{111}{1114}$ & $\operatorname{lll}_{1114}$ \\
\hline $\begin{array}{l}\text { Hypothetical protein } \\
(\mathrm{SCO} 3790)\end{array}$ & $\mid \begin{array}{ll} & \|_{\mathbf{l l}} \\
240 & 244\end{array}$ & $|\ldots|$ \\
\hline $\begin{array}{l}\text { DNA-directed DNA polymerase } \\
\text { (SCO3878) }\end{array}$ & |lll & $\left.\right|_{667}$ \\
\hline $\begin{array}{l}\text { Hypothetical protein, inositol-3-phosphate synthase } \\
\text { (SCO3899) }\end{array}$ & 864 & $\frac{11}{864}$ \\
\hline $\begin{array}{l}\text { DNA-directed RNA polymerase alpha chain } \\
\text { (SCO4729) }\end{array}$ & $\mid \frac{11}{728}$ & $\operatorname{lil}_{728}$ \\
\hline $\begin{array}{l}\text { ATP synthase alpha chain } \\
\text { (SCO5371) }\end{array}$ & 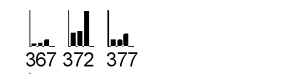 & $\left.\underset{367}{\ln } \ln _{372}\right|_{377}$ \\
\hline $\begin{array}{l}\text { Putative hydrolase, peptidoglycan catabolism } \\
\text { (SCO5466) }\end{array}$ & $\|_{1 .-}$ & -..- \\
\hline $\begin{array}{l}\text { Probable oxidoreductase } \\
\text { (SCO6061) }\end{array}$ & $\frac{.1}{1568}$ & $\|_{1568}^{\| l}$ \\
\hline $\begin{array}{l}\text { Oxidoreductase } \\
\text { (SCO7356) }\end{array}$ & $\frac{11}{1083}$ & $\frac{l_{11}}{1083}$ \\
\hline $\begin{array}{l}\text { Catalase A2 } \\
\text { (SCO7590) }\end{array}$ & $\varliminf_{317}$ & $\|_{317}$ \\
\hline
\end{tabular}

\footnotetext{
${ }^{a}$ Histograms bars represent relative spot intensities (the first, second and third bars are for time points zero, three, and $5 \mathrm{~h}$, respectively), and profiles are normalized to the maximum value for the protein. Histogram representation allows comparison for a single protein between the two strains and at the three different time points, but does not allow comparison between proteins. Numbers below histograms correspond to protein spots 2D gel (Figure 4).
}

play a role primarily in the control of spore wall thickness (unpublished). In our future projects, we intend to inactivate orf SCO5466 in order to confirm its presumed function in regulating the cell wall thickness in spores and therefore its role in germination.

Finally, our proteomic data do not allow speculation on putative Crp-dependent proteins responsible for the loss of actinorhodin production in the SAF1 mutant.

New Possible Targets of Morphological Differentiation. One of the aims of our proteomic study was to highlight new possible targets for further investigations on genes involved in morphological differentiation of streptomycetes. According to the fact that most molecules triggering the various steps of the development are extracellular, ${ }^{17}$ we take a special interest to receptor/transporter elements able to sense extracellular signals and transfer the information into the cell. Two proteins with such a presumed sensing/transporting function were selected in the proteome analysis due to their drastic divergent expression profile in SAF1 compared to M145. These two proteins (SCO2978, spot 690; SCO5477, spot 278) are all homologues to ligand-binding elements of ATP-binding cassette (ABC) transporters. SCO2978, and SCO5477 possess, respectively, a sugar and a oligopeptide-binding domain. They are all found within operons coding for the others elements of the ABC-transporter (permeases and ATP-binding component). Both proteins are present in quite constant and high amounts in SAF1 compared to low amounts and/or decreasing profiles in the wild type (Table 1). However, as deduced for PstS, this type of proteins should not have been detected through our method of soluble protein preparation. Post-translational modifications such as ADP-ribosylation can prevents the exportation of these proteins to the surface and therefore inhibit their function in transport. ${ }^{18}$ Interestingly, an earlier study aimed at isolating morphogenesis-dependent ADP-ribosylated proteins exclusively identified ligand-binding elements of $\mathrm{ABC}$ transporters in S. coelicolor. ${ }^{18}$ The sites for ADP-ribosylation reactions often are cysteine residues, which correlates well with the conserved lipobox cysteine predicted to be lipidated in the $\mathrm{N}$-terminal part of all known ADP-ribosylable proteins of $S$. coelicolor. ${ }^{18}$ We observed that the putative ADP-ribosylable cysteine was also conserved in our three target proteins (Figure 5) and included in the cleavage site consensus sequence in the signal peptide. SCO2978, SCO5477, and of course PstS are then good candidates for ADPribosylation, which could explain their presence in the soluble fraction of our spores preparation. Their cytoplasmic accumulation due to a presumed increased ADP-ribosylation in the SAF1 strain could inhibit the sensing and transport of molecules inducing and/or inhibiting one or more steps of morphological differentiation. Finally, proteins with unknown function or function not yet related to cell development present statistically significant increases or decreases in the SAF1 mutant compared to M145 (Table 1). This absence of data 


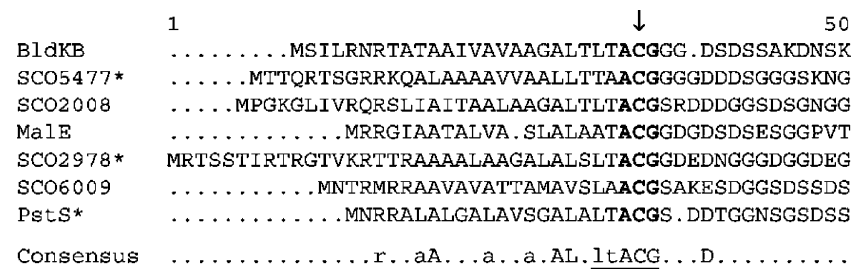

Figure 5. Multiple alignment of the $\mathrm{N}$-terminal part of known and presumed ADP-ribosylable protein in S. coelicolor. Residues conserved in all proteins are highlighted. The arrow indicates the conserved lipobox cysteine residue predicted to be ADPribosylated and lipidated. The asterisk indicates proteins identified from our proteomic analysis. The lipobox is underlined in the consensus sequence. BIdKB, $A B C$ oligopeptide transporter; MaIE, maltose-binding protein; SCO2008, putative ABC-type transporter of branched-chain amino acids; SCO2978, ABC-type sugar-binding protein; SCO4142 or PstS, ABC-type phosphatebinding protein; SCO5477, ABC-type oligopeptide transporter; SCO6009, ABC-type solute-binding protein.

Table 2. Summary of Phenotypes of the Diverse S. coelicolor Strains Affected Either in the Synthesis of cAMP or the Expression of $\mathrm{Crp}^{a}$

\begin{tabular}{lcccc}
\hline & $\begin{array}{c}\text { M145 } \\
(\text { WT })\end{array}$ & $\begin{array}{c}\text { SAF1 } \\
\left(\text { crp }^{-}\right)\end{array}$ & $\begin{array}{c}\text { SAF2 } \\
\left(\text { crp }^{+++}\right)\end{array}$ & $\begin{array}{c}\text { BZ1 } \\
\left(c y a^{-}\right)\end{array}$ \\
\hline growth & + & --- & + & - \\
germination & + & --- & $\mathrm{b}$ & -- \\
aerial hyphae & + & ++ & $\mathrm{b}$ & $+\mathrm{b}$ \\
sporulation & + & +++ & $\mathrm{b}$ & $+\mathrm{b}$ \\
$\gamma$-actinorhodin & + & --- & ++ & +--
\end{tabular}

${ }^{a}$ b, bald phenotype; + , phenotype similar to the wild type (WT) $S$ coelicolor A3(2) M145; ++ to +++ , phenotype enhanced or process accelerated compared to the WT; - to --- , phenotype absent or process delayed compared to the WT. Superscript letters in the BZ1 strain indicate the phenotype observed on unbuffered media.

prevents us to integrate them in our discussion but, obviously, we regard these ORFs as privileged targets for upcoming gene disruption aimed at integrating novel protagonists in the complex model of streptomycetes morphological differentiation.

\section{Conclusions}

The $\operatorname{crp}$ null mutant, affected in both spores formation and germ tube emergence, was considered as a privileged strain to study the shift from dormant to germinating spores. Earlier studies by our group showed that in vitro experiments are currently in a "dead end" situation as it is still not possible to demonstrate positive DNA-protein interaction between pure Crp and the presumed target cis-acting elements. ${ }^{7}$ In such a context, our proteomic approach -in combination with complementary in vivo studies and the analysis of the morphological properties of the spores mutant- revealed to be an appropriate alternative to highlight new perspectives in this topic. In fact, the identified proteins brought plausible explanations for most of known phenotypes of the crp mutant: (i) impaired germination, (ii) growth delay, and (iii) accelerated morphological differentiation.

Our work demonstrated that Crp, through its presence or its absence, could be considered as a central regulatory protein of all steps of cell development. Table 2 gives a summary of all phenotypes presented by the diverse $S$. coelicolor strains either affected in the synthesis of cAMP or the expression of Crp, the cAMP-binding regulatory protein. However, Crp target genes and Crp cis-acting elements are still unknown, and therefore this lack of knowledge prevents us to integrate our proteomic results into a model of a direct Crp-dependent regulation. Although the conditions to perform in vitro DNA-protein interactions with pure Crp are not yet established, we intend to perform ElectroMobility gel Shift Assays (EMSAs) on the promoter regions of all deduced Crp-dependent ORFs with protein extracts from M145 and SAF1 strains. ChIP to Chip experiments are also programmed in the future and should provide data that would be considered as the starting point to differentiate between proteomic changes that are directly or indirectly dependent on the deletion of crp.

One of the aims of our proteomic study was to highlight new possible targets for further investigations on genes involved in streptomycetes morphological differentiation. We already mentioned that a difficulty inherent to our study of germination is to discern between changes in the true early signaling events and the awakening of essential metabolism. Our work provided significant evidences indicating a general lower response to spore activation in mutant SAF1 due to abnormally low activity of proteins involved in the essential metabolism (protein synthesis, transcription machinery, and the respiratory chain). Besides these central proteins, three orfs coding for peptides with predicted sensing/transporting functions were identified due to their drastic divergent expression profile in SAF1 compared to M145. In fact, three membrane anchored ligandbinding elements of $\mathrm{ABC}$ transporters presented an abnormal cytoplasmic localization suggesting the loss of their function in transport of molecules. In addition, all the three proteins are privileged target for ADP-ribosylation, a post-translational modification related to morphological differentiation. The intracellular presence of these proteins in our SAF1 hypersporulating mutant could be the consequence of an enhanced ADP-ribosylation. This hypothesis is in agreement with the phenotypes of $\operatorname{brg} A, b l d B, b l d C$, and bldH mutants, all blocked in aerial hyphae formation and presenting a decrease of the global ADP-ribosylation activity. ${ }^{19}$ The identification of proteins no more ribosylated in these diverse bald mutants would indicate whether SCO2978, PstS, and SCO5477 are cell development sensors depending on this post-translational modification.

In conclusion, our proteomic approach has largely contributed to open new perspectives in the understanding of the Crp regulon in $S$. coelicolor. Recently, genome sequencing has revealed that Crp orthologues are present in various nondifferentiating actinomycetes species, notably GlxR in Corynebacterium glutamicum ${ }^{20}$ and RV3676 in Mycobacterium tuberculosis. $^{21}$ Proteins spots not related to morphological differentiation identified in our work could be considered as alternative information to decipher the Crp regulon in other actinomycetes.

Acknowledgment. This work was funded by a "Crédit d'Impulsion" and "fonds spéciaux pour la recherche" of the Université de Liège. Support was also received through Grant No. 9.4573.04 of the Belgian Fund for Scientific Medical Research to P.L., grants SFB473 and GK805 of the Deutsche Forschungsgemeinschaft to F.T. and by a grant from the Royal Netherlands Academy for Arts and Sciences (KNAW) to G.P.v.W. A.P. is a researcher of the patrimoine of the University of Liège and A.D. a research fellow of the Fund for Research in Industry and Agriculture (FRIA). S.R. is a postdoctoral research assistant 
of the patrimoine of the University of Liège. P.L. is a Research Associate of the Belgian National Fund for Scientific Research.

Supporting Information Available: Details of protein identifications by mass spectrometry. This material is available free of charge via the Internet at http://pubs.acs.org.

\section{References}

(1) Chater, K. F. Annu. Rev. Microbiol. 1993, 47, 685-713.

(2) Mikulik, K.; Bobek, J.; Bezouskova, S.; Benada, O.; Kofronova, O. Biochem. Biophys. Res. Commun. 2002, 299, 335-342.

(3) Eaton, D.; Ensign, J. C. J. Bacteriol. 1980, 143, 377-382.

(4) Bobek, J.; Halada, P.; Angelis, J.; Vohradsky, J.; Mikulik, K. Proteomics 2004, 4, 3864-3880.

(5) Susstrunk, U.; Pidoux, J.; Taubert, S.; Ullmann, A.; Thompson, C. J. Mol. Microbiol. 1998, 30, 33-46.

(6) Derouaux, A.; Halici, S.; Nothaft, H.; Neutelings, T.; Moutzourelis, G.; Dusart, J.; Titgemeyer, F.; Rigali, S. J. Bacteriol. 2004, 186, 1893-1897.

(7) Derouaux, A.; Dehareng, D.; Lecocq, E.; Halici, S.; Nothaft, H.; Giannotta, F.; Moutzourelis, G.; Dusart, J.; Devreese, B.; Titgemeyer, F. Biochem. Biophys. Res. Commun. 2004, 325, 983-990.

(8) Kieser, T.; Bibb, M. J.; Buttner, M. J.; Chater, K. F.; Hopwood, D. A. Pratical Streptomyces Genetics; The John Innes Foundation: Norwich, 2000.
(9) Raskin, C.; Gerard, C.; Donfut, S.; Giannotta, E.; Van Driessche, G.; Van Beeumen, J.; Dusart, J. Cell. Mol. Life Sci. 2003, 60, 14601469 .

(10) Rabilloud, T.; Strub, J. M.; Luche, S.; van Dorsselaer, A.; Lunardi, J. Proteomics 2001, 1, 699-704.

(11) Lamanda, A.; Zahn, A.; Roder, D.; Langen, H. Proteomics 2004, 4, 599-608.

(12) Keijser, B. J.; Noens, E. E.; Kraal, B.; Koerten, H. K.; van Wezel, G. P. FEMS Microbiol. Lett 2003, 225, 59-67.

(13) van Wezel, G. P.; van der Meulen, J.; Kawamoto, S.; Luiten, R. G.; Koerten, H. K.; Kraal, B. J. Bacteriol. 2000, 182, 5653-5662.

(14) Chakraburtty, R.; Bibb, M. J. Bacteriol. 1997, 179, 5854-5861.

(15) Ochi, K. J. Gen. Microbiol. 1986, 132, 299-305.

(16) Diaz, M.; Esteban, A.; Fernàndez-Abalos, J. M.; Santamaria, R. I. Microbiology 2005, 151, 2583-2592.

(17) Kelemen, G. H.; Buttner, M. J. Curr. Opin. Microbiol. 1998, 1, 656662.

(18) Sugawara, K.; Dohmae, N.; Kasai, K.; Saido-Sakanaka, H.; Okamoto, S.; Takio, K.; Ochi, K. Biosci. Biotechnol. Biochem. 2002, 66, 2292-2296.

(19) Shima, J.; Penyige, A.; Ochi, K. J. Bacteriol. 1996, 178, 3785-3790.

(20) Kim, H. J.; Kim, T. H.; Kim, Y.; Lee, H. S. J. Bacteriol. 2004, 186, 3453-3460.

(21) Spreadbury, C. L.; Pallen, M. J.; Overton, T.; Behr, M. A.; Mostowy S.; Spiro, S.; Busby, S. J.; Cole, J. A. Microbiology 2005, 151, $547-556$.

PR050155B 